\title{
The Evolution of Digital Technologies - from Collaboration to eCollaboration - and the Tools which assist eCollaboration
}

\author{
Michael Jones \\ Faculty of Commerce, University of Wollongong, \\ Wollongong, Australia
}

miones@uow.edu.au

\begin{abstract}
Collaboration, where firms share skills and/or resources in order to fulfill a common goal is not a new concept. Firms have been collaborating since the beginning of time. Projects like the Great Pyramids of Giza and the Great Wall of China could not have been completed without the collaboration of teams of people. However, while the objectives of those who engage in collaborative activities has hardly changed over time, the advent of the computer and the digital age has markedly changed how these firms engage with each other and how they cooperate to fulfill their objectives.

This paper will take the reader through a journey of discovery to learn how collaboration has transformed to become eCollaboration. The paper will uncover the evolution of digital technologies which has instigated this transformation and how essential these electronic tools have become for the enablement of successful and sustainable collaboration. Finally, the paper will present a suite of tools which are currently available to assist firms in their eCollaboration endeavors. This final element represents a unique contribution to this body of knowledge and enables a contribution to practice through a meta-analysis of tools, their utility and application.
\end{abstract}

Keywords: Collaboration, eCollaboration, Information Systems, Communication, knowledge Management

\section{Introduction}

The foundations of modern business are built on two accepted principles of economic competition. These are the resource-based view (RBV) (Hamel \& Ruben, 2000; Prahalad \& Hamel, 1994), and the market-based view (MBV) (Porter, 1985). Businesses employing the former RBV - gain and maintain competitive advantage through their strategic management and preservation of scarce resources. These resources are the core strengths of the company and include

Material published as part of this publication, either on-line or in print, is copyrighted by the Informing Science Institute. Permission to make digital or paper copy of part or all of these works for personal or classroom use is granted without fee provided that the copies are not made or distributed for profit or commercial advantage AND that copies 1) bear this notice in full and 2) give the full citation on the first page. It is permissible to abstract these works so long as credit is given. To copy in all other cases or to republish or to post on a server or to redistribute to lists requires specific permission and payment of a fee. Contact Publisher@InformingScience.org to request redistribution permission. both tangible assets - for example process inputs and capital structures, and intangible assets like capabilities, processes and knowledge. In RBV, key strategic value is gained through resources which are valuable, rare, inimitable and non- substitutable (Barney, 1991). Alternatively, MBV takes a competitive approach to firm survival. With MBV, firms contend against one and other to gain market advantage through an active 
identification of opportunities and by strategically dominating disruptions in the market. MBV is driven by Porter's (1985) Five-Forces framework, which enables firms to assess potential opportunities through an analysis of five elements or market forces. These are: (1) the threat of the entry of new competitors; (2) the threat of substitute products or services; (3) the bargaining power of customers (buyers); (4) the bargaining power of suppliers; and (5) the intensity of competitive rivalry.

Most firms today subsist in a super-competitive environment. Strategies like RBV and MBV, which promote a protectionist and exploitive agenda, are not enough for firms to maintain a sustainable competitive position in their market (Makhija, 2003). Businesses are increasingly faced with the need to collaborate to maintain a competitive foothold (Berasategi, Arana, \& Castellano, 2011; Pfohl, Hofmann, \& Trumpfheller, 2005). Firms which successfully collaborate and create functional partnerships can realize additional benefits through an RBV and MBV position. Firstly, firms can concentrate more clearly on their actual core competencies, leaving fellow collaborators to concentrate on theirs. Therefore, through collaborative complementarity, real synergies can be leveraged (Eschenbächer, Kück, \& Weiser, 2001). Secondly, collaboration, especially where forward vertical integration is utilized, can expand market opportunities (Ulbrich, Troitzsch, van den Anker, Plüss, \& Huber, 2011).

In the context of business, collaboration is a process through which two or more firms work together to achieve some practical outcome. In so doing, they will generally share resources and commit to a mutually shared goal (de Vreede, Briggs, \& Massey, 2009). Collaboration also involves "a process of decision making among interdependent parties; it involves joint ownership of decisions and collective responsibility for outcomes” (Liedtka, 1996, 21).

There is a large but subtle difference between collaboration and eCollaboration. The difference being that the latter engages technology to facilitate and enhance the processes of collaboration. Mayrhofer and Back define eCollaboration as a "computer mediated process of two or more (dislocated) people working together on a common purpose or goal, where the participants are committed and inter-dependent and work in a common context using shared resources, supported by (web-based) electronic tools" (2003, 7). Technology therefore permits collaborators the flexibility of working together "on a virtual dimension, regardless of time and location" (Fong, 2005, vi). eCollaboration is increasingly becoming more common place amongst businesses. Through eCollaboration the interface between firms changes and can take a multitude of forms. Most common are the Internet and email. However, businesses can embrace a range of tools from as simple as a mobile phone or SMS (text) through to complex systems like wiki, teamspace, and other management information systems. Through eCollaboration, stakeholders are able to network between the fields of computer-human interaction, computer-supported cooperative work, and electronic commerce.

eCollaboration presents participants with market advantages. A commonality of information exchange enables an expedient path of communication that establishes a sense of exclusivity to only those members with collaborative access (Ma, 2009). Seamless knowledge management and storage can be achieved (Meixner \& Haas, 2008). Transaction costs can be reduced, and a wider mix of stakeholders can be included in transactions with a minimal marginal expense (Meixner \& Haas, 2008). Businesses can leverage value creation through enhanced inter-partner learning and by "combining internal and external resources in innovative ways" (Ma, 2009, 68). Shared information systems facilitate the optimization of supply chains, the reduction of inventory and the mitigation of risk. This results in improved customer service and enhanced forecasting and planning (Ma, 2009). Elements of intercultural conflict, which are frequently present in conventional forms of collaboration, may be avoided as a result of the more flexible and fluid constraints of the virtual environment associated with eCollaboration (Stern \& Hicks, 2000). 
Business managers have long acknowledged the value of collaboration through specialization: "resource owners increase productivity through cooperative specialization" (Alchian \& Demsetz, 1972, 777). eCollaboration is much like Henry Ford's conveyer belt, except instead of pockets of specialization existing along the conveyor belt, pockets of specialization exist along the ether of the internet, with each firm performing a narrow range of value-adding activities along the way (Dyer, 2002; Kuehn, 2005).

A wide range and variety of e-technologies are available for use by businesses to enable and assist eCollaboration. However, often these tools are difficult to adopt and use, and the very variety and range that improves their utility also stifles their adoption because businesses do not have the resources to scan tools, compare their differences, and assess their value. This is especially important in the case of small businesses, who have limited skills in areas of information technology and information systems (Burgess \& Sargent, 2007; Enright \& Roberts, 2003; Simpson \& Docherty, 2004).

The next section will discuss the evolution of electronic technologies and the developmental role they have played in collaboration and communication. Following this, the paper will present an assessment of current tools for eCollaboration. It is hoped that imbued with this information business practitioners may begin to journey down the road towards technological adoption and eCollaboration.

\section{Who put the ' $e$ ' in eCollaboration}

There is no doubt that the development of the internet has liberated individuals and businesses from the shackles of conventional society. The seeds for electronic collaboration were sown in the very early days of the internet with groups of people congregating around similar interests. During these pre-connected times - around 1988, tools like Internet Relay Chat (IRC) and Bulletin Board Systems (BBS) were created. The early 1990s brought about the introduction of graphical web browsing, especially with the arrival of Netscape in 1994. This revolution moved people to more accommodating means of communication. Internet forums and message boards began life and chat and instant messaging began taking an earnest hold among e-socialites. At the same time, an increase in the number of internet providers and an increase in access speed and bandwidth coupled with reduced access costs saw a tidal flow of personal webpages where individuals could communicate to (not with) the world.

The next generation of social tools quickly followed. MySpace arrived and was soon followed with FaceBook. Weblogs (Blogs) began to untether the masses and create a multitude of sites dedicated to an ever increasing array of diverse interests. Instant messaging continued to evolve, and micro-blogging arrived in the form of Twitter and its variants.

The most recent advances in the field have permitted even more effective and efficient communication and collaboration through the use of wireless technologies. Using internet enabled devices like smartphones and tablets, individuals can now maintain contact and communication almost regardless of the environment or time.

Throughout this period, and even earlier (primitive forms of email existed as far back as 1965 (Peter, 2004)) email has remained the primary tool for communication and collaboration, serving individual and business person alike. Similarly communication and collaboration have been enabled and enhanced through other parallel technologies. Mobile phones have enhanced availability through wireless communication, and have also enabled texting through their Short Messaging Service (SMS).

This evolution of technologies for communication and collaboration are just at the beginning of their development. There are currently 6.9 billion individual connections to the internet (Internet 
World Stats, 2011), with some people having multiple connections, e.g.: home, office, phone. Coincidentally, this is the same number as the current world population. Asia has almost 4 billion of this number, yet they represent only $24 \%$ penetration, as a result the number of connections will grow dramatically in the next few years. This vast number of users is increasingly identifying diverse needs for communication and socialization. Consequently, tools are being developed at an ever-increasing rate, and this development will assist businesses in solving their needs for collaboration.

\section{Tools to Use}

Collaboration occurs in one of two ways. Either, all parties work together at the same time, and usually in the same space - this is known as synchronous collaboration, or they can work separately utilizing different time and space zones - this is known as asynchronous collaboration. Electronic tools work well to enhance asynchronous collaboration. Electronic tools also work well in situations where synchronous collaboration is dominant, however, their use is not as necessary.

Based on this division of needs, the discussion on tools, which follows, will be divided into two major sections: 1) Asynchronous tools and 2) Synchronous tools. The section on asynchronous will be further divided into five areas, these are: 1) Communication Tools, 2) Information Sharing Tools, 3) Group Calendar Tools, 4) Social Networking Tools, and 5) Integrated Systems - this categorization builds on the work of (Xu, Zhang, Harvey, \& Young, 2008) whose research evaluated at a range of asynchronous tools for collaboration. The discussion which follows will introduce a range of contemporary tools for the interest of researchers and practitioners. For practitioners in particular, a summary table will follow each section which will provide a checklist of each tool, its most beneficial features 'what can it do?' and the value it may provide to the collaborator 'Why should you be using it?'

\section{Asynchronous Collaboration}

The real advantage of asynchronous collaboration is that it is non-simultaneous. That is, it happens at the convenience of each individual member. Early tools used for enhancing asynchronous collaboration were email, newsgroups, bulletin boards and web logs (Xu, et al., 2008). The tools discussed in this section tend to be extensions and/or integrations of these early building blocks.

\section{1) Communication Tools}

The primary function of communication tools is to enable collaboration through the exchange of messages and information.

Email is still the most popular form of communication. However, email today is far more advanced than it was when the internet was struggling for identity. The advanced features of email which assist collaboration are filtering, filing, creation of mail groups, and document attachment. Most email tools also include basic systems for creating calendars and scheduling meetings. New forms of email are also now cloud based utilizing HTTP email. The three largest providers of HTTP email are Gmail (mail.google.com), Hotmail (Hotmail.com), and Yahoo Mail (mail.yahoo.com). By utilizing these cloud-based variants, users can maintain all of the functionality of peer-to-peer (P2P) based systems, however additional advantages are gained through mobility. For example, email can be accessed on any computer, at any time, and mobile email can be used on smartphones and tablets. Other providers of HTTP email are: AOL Mail (mail.aol.com); BigString (bigstring.com); Excite Mail (mail.excite.com); FlashMail (flashmail.com); GMX Mail (gmx.com); Inbox.com (inbox.com); Lycos Mail (mail.lycos.com); Mail.com (mail.com); Zoho Mail (zoho.mail.com) (Miller, 2008). 
Newsgroups are an extension of email. However, newsgroups tend to be demand based, where a participant can choose to 'opt in'. Newsgroups enable members of a collaborating venture to share information of a more general nature. They are an important element of collaboration in maintaining a sense of project currency, and in ensuring that all members are equally up-to-date with all information on the project. As a result, they help to breakdown communication barriers and reduce inequities.

Instant Messaging Services (IMS) are another evolution of email. The main difference between the two is that emails are delivered in a virtual envelope, which must be opened to be read. IMS or Chat provides a means of communicating more directly and more instantaneously. However, the real advantages of chat are only truly realized in a synchronous communication environment, so chat will be discussed in greater detail in the section on Synchronous Collaboration below.

Microblogging. Twitter is the most widely used application for microblogging. Microblogs or twits are very short (and usually highly abbreviated) messages of around 140-160 characters (Hastings, 2009). These twits are sent to people who have subscribed to 'follow' the twitter. Twitter is perhaps best used in the sense of collaboration to maintain status updates. For example, a project working on the development of new mining drills can set up the monitoring equipment to twit status reports on the drills progress into a substrate. All project members interested in receiving status updates can then follow the twit feeds. Twits are brief and frequent, they are therefore useful in communicating important information which requires instant interpretation.

\section{Table 1: Summary of Communication Tools}

\begin{tabular}{|l|l|l|}
\hline Tool & What can it do? & Why should you be using it? \\
\hline Email & $\begin{array}{l}\text { Exchange of complex mes- } \\
\text { sages. } \\
\text { Group communication. } \\
\text { Meeting scheduling. }\end{array}$ & $\begin{array}{l}\text { Through the use of mail groups, email should } \\
\text { be used regularly to maintain contact with } \\
\text { members. Also, by enabling time transparency } \\
\text { on each member's calendar, meetings can be } \\
\text { scheduled with ease and confidence. }\end{array}$ \\
\hline Newsgroups & Provide information circulars. & $\begin{array}{l}\text { To maintain a sense of currency among all par- } \\
\text { ticipants, and to break down barriers of com- } \\
\text { munication and perceived inequities. }\end{array}$ \\
\hline Microblogs & $\begin{array}{l}\text { Provide quick and brief project } \\
\text { status updates. }\end{array}$ & $\begin{array}{l}\text { When instantaneous feedback is required in } \\
\text { precarious or urgent situations microblogs en- } \\
\text { able easy access to basic information. }\end{array}$ \\
\hline
\end{tabular}

\section{2) Information Sharing Tools}

Blogs are frequently modified web pages in which dated entries are listed in reverse chronological sequence (Jones \& Alony, 2008). Traditionally, Blogs are a combination of diary, web site, and online community (Embrey, 2002). Typically, they are personal journals which are published online, and are frequently updated with links to similar and related topics, often from other bloggers. This interconnection of blogs is known as 'the blogosphere'. From the perspective of the collaboration, Blogs are often used by content experts to share knowledge pertaining to specific elements of the collaboration. For example, a team working on developing business expansion into China may contain experts on Chinese culture, on international law, etc. These experts could then share project-specific knowledge through a Blog. In so doing, they may discuss a recent issue, for instance, the protocol around meeting business executives in China. As the Blog is shared amongst the whole team, every member has access to this knowledge, and can ask questions or engage with the author in other ways. The knowledge that is created is saved as project IP, and important information is not missed, nor does it need to be repeated. 
Discussion Forums are an extension of the original Bulletin Board Systems. They provide a platform upon which problems and issues can be explored, and knowledge can be created and stored. For example, a team collaborating on the development of a fuel efficient engine may start by creating a thread looking at variations in fuel performance. Other members of the team may then post replies, upload supporting evidence, or create additional threads. After a period of time a great amount of information can be harvested on one or many issues around a project. The tool serves as a sound vehicle for brainstorming and problem resolution. Discussion Forums can be open or closed. If closed, only project members have access, and only their joint expertise can be utilized. If they are open, they are open to the world and creative solutions may result through the power of crowd sourcing, however when they are open sensitive information needs to be carefully managed.

Wikis are a combination of blogs and discussion forums. The best known example of a wiki is Wikipedia (wikipedia.org). A Wiki is a communal webpage which permits every member of a team or project to add or edit information. Therefore knowledge is created through multiauthorship. A "wiki taps into the 'wisdom of the mob' principle” (Fernando, 2005, 8), and its value grows as more people start using it. Wikis are, therefore, a useful environment in which teams can create group documents. For example, the project leader may create a table of contents, members can then fill-in or edit various sections as the document grows. Wikis usually maintain a version history (version control), so previous edits are retained and can be reborn if required. Given that the word wiki comes from the Hawaiian word for 'fast' (Miller, 2008) wiki's provide a fast and efficient means of document and knowledge creation. Usually no special knowledge of the internet is required - e.g. HTML. A popular and free provider of the wiki platform is MediaWiki (mediawiki.org). Other versions of wiki can be found at: PBwiki (pbwiki.com); Versionate (versionate.com); wikihost.org site (wikihost.org); Wikispaces (wikispaces.com); and Zoho Wiki (wiki.zoho.com).

Online Documents are web-based document management systems that provide a means of sharing and co-authoring documents online through cloud sourcing. Online documents differ from wikis, in respect to document creation, as they enable the creation of more complex documents and permit a more formal - and more widely accepted - presentation format - similar to those products offered by MS Office. Collaboration is enabled in these documents, merely by inviting a colleague to co-author a selected document through an email invitation. A typical suite of tools for online documenting is Google Documents (docs.google.com). on this site Google provide users with MS Office-like tools such as: word processing; spreadsheets; presentations; forms; and drawings. Another tool is Zoho Office (zoho.com). All of these tools permit version control.

Virtual File sharing tools provide a collaborative space on the cloud where participants can share files and documents. Enabling these tools is often as simple as creating a folder (or directory) on your PC and then linking it to a virtual folder over the internet. A popular tool is Dropbox (dropbox.com) which allows collaborators to invite others to share folders and files. These files can then be accessed anywhere and anytime, including through smartphones. Most also provide version control, and maintain a backup of deleted files. Other tools available are: Syncplicity (syncplicity.com); Windows Live Mesh (explore.live.com/windows-live-mesh); SpiderOak (spideroak.com); SugarSync (sugarsync.com); and Wuala (wuala.com). 
Table 2: Summary of Information Sharing Tools

\begin{tabular}{|l|l|l|}
\hline Tool & What can it do? & Why should you be using it? \\
\hline Blogs & $\begin{array}{l}\text { Quick way of sharing infor- } \\
\text { mation from subject experts } \\
\text { on matters of joint impor- } \\
\text { tance. }\end{array}$ & $\begin{array}{l}\text { To ensure the knowledge and experiences of your } \\
\text { collaboration experts are put to best use. This tool } \\
\text { breaks any communication blockages by ensure } \\
\text { that every member has equal access to every ex- } \\
\text { pert. }\end{array}$ \\
\hline $\begin{array}{l}\text { Discussion } \\
\text { Forums }\end{array}$ & $\begin{array}{l}\text { Enhance brainstorming. } \\
\text { Assist in problem solving. } \\
\text { Increase creativity and inno- } \\
\text { vation. }\end{array}$ & $\begin{array}{l}\text { Discussion forums push members outside of their } \\
\text { collective 'box'. By sharing problems and inviting } \\
\text { solutions innovative ideas will result, and group- } \\
\text { think will be minimized. }\end{array}$ \\
\hline Wikis & $\begin{array}{l}\text { Create collaborative docu- } \\
\text { ments. } \\
\text { Capture knowledge. }\end{array}$ & $\begin{array}{l}\text { This is an excellent tool for creating documents, } \\
\text { especially where various sections require input } \\
\text { multiple collaborators. }\end{array}$ \\
\hline $\begin{array}{l}\text { Online } \\
\text { Documents }\end{array}$ & $\begin{array}{l}\text { Create complex collaborative } \\
\text { documents in a multitude of } \\
\text { forms similar to MS Word, } \\
\text { Excel, PowerPoint, etc. }\end{array}$ & $\begin{array}{l}\text { These tools are simple to use, but provide powerful } \\
\text { collaboration enhancement. They are excellent } \\
\text { tools to use for sharing and creating any document. }\end{array}$ \\
\hline $\begin{array}{l}\text { File shar- } \\
\text { ing }\end{array}$ & $\begin{array}{l}\text { Store and share files of any } \\
\text { type with cloud access. }\end{array}$ & $\begin{array}{l}\text { It permits virtual storage of all project files, ena- } \\
\text { bling access by all (or selected) members of the } \\
\text { team for creation or modification. }\end{array}$ \\
\hline
\end{tabular}

\section{3) Group Calendar Tools}

While many email programs include a calendar, a group calendar tool is a purpose built platform for group time management and scheduling. Some programs also provide support for scheduling of rooms and equipment. Usually these calendar tools will integrate into individual email-based calendars - like MS Outlook - especially through the use of iCal which allows synchronization of events via email. They provide multiple user access so that a host of people can see and manage the group's collaborative time. When seeking a calendar for collaborative purposes, it should permit easy sharing and reuse of data. This can be enabled through an RSS or XML data feed which allows users to receive automated notifications of events and alerts, this can also be streamed into a project webpage. It should also allow individuals to manage, block or blind periods of time in their personal calendars (Hastings, 2009). Ideally the calendar will allow a range of alarms and notification. While these are usually through emails and pop-up reminders, some systems will send alarms via SMS. Two calendars which are cloud-based are 30 Boxes (30boxes.com) and Google Calendar (Google.com/calendar). Other products are: Backpack Calendar (backpackit.com/calendar), Yahoo Calendar (calendar.yahoo.com), Airset (airset.com)

Table 3: Summary of Group Calendar Tools

\begin{tabular}{|l|l|}
\hline What can it do? & Why should you be using it? \\
\hline Schedule meetings and resources. & To more easily and effectively manage the time of \\
Find mutually available time. & project participants. To know, at a glance, who is \\
Alert participants of upcoming events & available, or who is doing what and where. \\
\hline
\end{tabular}

\section{4) Social Networking Tools}

As discussed above, the ubiquity of social networking tools is unparalleled in today's society. The need for individuals to communicate and stay 'in touch' has created an abundance of tools to meet this purpose. While these tools are designed with the 'social' in mind, this does not limit their potential for businesses to use them for collaboration and communication. The most popular 
tools for social networking which are, or can be, used for business collaboration are: Facebook (facebook.com), linkedin (linkedin.com) and MySpace (myspace.com). only the first of these will be discussed in detail. MySpace is very similar to Facebook, and therefore will not be discussed. Linkedin is a great tool for creating connections, promoting one's business, and selecting potential staff, it does not lend itself easily to a collaborative environment.

Facebook is being used by businesses more each day. While their use is predominantly for promotion and marketing, the tool also has many benefits for collaboration. Collaborators intending to use Facebook should begin by starting a business account. They should then create a group by inviting collaborators to join the group. Facebook allows you to create events, upload documents, and create chats and blogs. Projects contemplating using Facebook should carefully manage access to control who does or does not have read and/or write privileges to the site. 'Going viral' can be a real problem in this environment, if you make a mistake (photos from you wild drunken party for instance) and you do not carefully control access, you may find your photos circulating around the world in just seconds.

\section{Summary of Social Networking Tools}

While social networking tools are primarily free, and do have a range of useful Facilities. It is not recommended to adopt these for serious collaboration projects. The facilities are basic, and not very flexible, and the potentials for insecurity represent real problems.

\section{5) Integrated Systems}

Integrated systems are also known as groupware. These are usually a suite of web-based tools employed to assist collaborators with communication and project management. They assist collaborators in their communication, cooperation, coordination, problem solving, and negotiation, usually all in the one package. They differ from the stand-alone systems discussed above in their design - for instance a group 5 people using a particular software system will have different needs and experience different dynamics than will a group of 500 people. So groupware products are design with ease of use, flexibility and individual tolerances and homogeneity in mind. Systems are more robust with increased reliability and endurance.

These integrated systems usually include the following discrete tools (Miller, 2008):

- File and document uploading and sharing

- Web calendar

- Task/project manager

- Message boards

- Text-based chat rooms / instant messaging

- Wiki-like collaborative pages

- Blogs

The advantage of this one-stop-shop approach is that all of the tools are located in one place, in one common platform, and as a result can be accessed by all group members, with minimal training. Some common groupware products are: AirSet (airset.com); ContactOffice (contactoffice.com); Google Sites (sites.google.com); Huddle (huddle.net); Nexo (nexo.com); OpenTeams (openteams.com); ProjectSpaces (projectspaces.com); and teamspace (teamspace.com)

Table 4: Summary of Integrated Systems

\begin{tabular}{|l|l|}
\hline What can it do? & Why should you be using it? \\
\hline $\begin{array}{l}\text { Usually everything, but this is usually } \\
\text { at a price. }\end{array}$ & $\begin{array}{l}\text { Large teams and collaborations should consider group- } \\
\text { ware first. The overall cost will be mitigated by im- } \\
\text { provements in use, and reduced overall training costs. }\end{array}$ \\
\hline
\end{tabular}




\section{Synchronous Collaboration}

Synchronous collaboration generally requires participants to be present in one form or another. This can be on the internet, over the phone, or in person. The advantages of synchronous collaboration are that people receive immediate feedback, and can more dynamically work with each other to create ideas or solve problems. Early tools used for enhancing synchronous collaboration were web conferencing, whiteboarding and instant messaging (Xu, et al., 2008). The tools discussed in this section tend to be extensions and/or integrations of these early building blocks.

Whiteboarding is a tool which allows multiple users to simultaneously write and draw on a webbased canvas in real-time. The tool promotes thinking, brainstorming, designing and problem clarification. It is often used during phone conversations where people can share notes and collaborate graphically. Some whiteboarding products are: Dabbleboard (dabbleboard.com); ScribLink (scriblink.com); CoSketch (cosketch.com); Scribblar (scribbler.com); GroupBoard (groupboard.com); and skrbl (skrbl.com).

Video Conferencing is traditionally costly. However, through Skype, and with the popularity of videos on computers, video conferencing is becoming more realistic. Video has the most advantage when visual elements are critical to the communication. It is however awkward, it can be slow, and a high level of knowledge is required when the video involves more than two participants. Some products which support video conferencing are: Cisco Webex (webex.com); IBM Sametime (ibm.com/software/lotus/sametime); Adobe Connect (adobe.com/products/adobeconnect); and Go To Meeting (gotomeeting.com). Some of these programs also include other functions for collaboration.

Instant Messaging (Chat) permits the instantaneous exchange of ideas by a large number of people. One clear advantage of chat systems is that a transcript of the 'conversation' can be obtained at the end of the session. Products available to support instant messaging are VaporStream (vaporstream.com); Windows Live Messenger 2011 (explore.live.com/messenger); Yahoo! Messenger 10 (messenger.yahoo.com); AIM (www.aim.com); and Trillian Astra (www.trillian.im).

Short Message Service (SMS) is a feature commonly associated with mobile phones, and is usually used in a mobile-to-mobile context. However, new internet provided services are enabling computer to mobile and computer to land-line services. In addition, on line services like FollowUpThen (followupthen.com) are enabling SMS alerting services via email. The power of SMS for business collaboration should not be overlooked. Response rates to communication channels show that mobile phone calls receive greatest response, and this is followed closely by text (SMS) notifications. Texts are quick and usually follow people wherever they go. With the use of smartphones, text can also be sent to groups of people.

Table 5: Summary of Synchronous Collaboration Tools

\begin{tabular}{|l|l|l|}
\hline Tool & What can it do? & Why should you be using it? \\
\hline Whiteboarding & $\begin{array}{l}\text { Enhance collaboration through the } \\
\text { creation of creative environments for } \\
\text { simultaneous input by two or more } \\
\text { people. }\end{array}$ & $\begin{array}{l}\text { When time constraints are tight and solutions } \\
\text { and ideas are needed quickly whiteboarding } \\
\text { provides a quick and easy answer. }\end{array}$ \\
\hline $\begin{array}{l}\text { Video Confer- } \\
\text { encing }\end{array}$ & $\begin{array}{l}\text { Link two or more people together in } \\
\text { a virtual face-to-face environment. }\end{array}$ & $\begin{array}{l}\text { When communication requires additional clarity } \\
\text { or visual assistance. }\end{array}$ \\
\hline $\begin{array}{l}\text { Instant Messag- } \\
\text { ing }\end{array}$ & $\begin{array}{l}\text { Provide a quick exchange of ideas } \\
\text { and information. Discussions are } \\
\text { dynamic and lively and the exchange } \\
\text { can be recorded. }\end{array}$ & $\begin{array}{l}\text { Works well when information is required } \\
\text { quickly, and the information to be exchanged is } \\
\text { not too complex or comprehensive. }\end{array}$ \\
\hline $\begin{array}{l}\text { Short Message } \\
\text { Service }\end{array}$ & $\begin{array}{l}\text { SMS has excellent reach and re- } \\
\text { sponse capabilities. }\end{array}$ & When an answer is required immediately. \\
\hline
\end{tabular}




\section{Discussion and Conclusion}

Collaboration is an important ingredient in the success of most firms in today's market. Many firms collaborate successfully, but not all are aware of the host of technologies which are now available to assist them in their transition from collaboration to eCollaboration. This paper has presented a range of tools, both synchronous and asynchronous, which are available to practitioners. Further, this discussion provides a contemporary perspective on the development of technologies in the Information Systems sphere upon which academics may build in order to further develop their science.

\section{References}

Alchian, A. A., \& Demsetz, H. (1972). Production, information costs, and economic organization. The American Economic Review, 62(5), 777-795.

Barney, J. (1991). Firm resources and sustainable competitive advantage. Academy of Management Journal, 37, 680-687.

Berasategi, L., Arana, J., \& Castellano, E. (2011). A comprehensive framework for collaborative networked innovation. Production Planning \& Control: The Management of Operations (First published on: 09 February 2011 (iFirst) ).

Burgess, L., \& Sargent, J. (2007). Enhancing user acceptance of mandated mobile health information systems: The ePOC (electronic Point-Of-Care Project) experience. Studies in Health Technology and Informatics, 129(2), 1088.

de Vreede, G., Briggs, R., \& Massey, A. (2009). Collaboration engineering: Foundations and opportunities [Editorial to the Special Issue in the Journal of the Association of Information Systems]. Journal of the Association for Information Systems, 10(3), 121.

Dyer, J. H. (2002). Effective interfirm collaboration: How firms minimize transaction costs and maximize transaction value. Strategic Management Journal, 18(7), 535-556.

Embrey, T. R. (2002). You blog, we blog: A guide to how teacher-librarians can use weblogs to build communication and research skills. Teacher Librarian, 30(2), 7-9.

Enright, M. J., \& Roberts, B. H. (2003). Regional clustering in Australia. In I. Marsh (Ed.), Australia's choices : Options for a prosperous and fair society (pp. 67-88). Sydney: UNSW Press.

Eschenbächer, J., Kück, N., \& Weiser, B. (2001). Business and legal issues in enterprise collaborations: A German perspective. Production Planning \& Control: The Management of Operations, 12(5), 488503.

Fernando, A. (2005). Wiki: the new way to collaborate. Communication World, 1, 8-9.

Fong, M. W. L. (2005). E-collaborations and virtual organizations. Hershey PA: Irm Press.

Hamel, G., \& Ruben, P. (2000). Leading the revolution (Vol. 286): Boston: Harvard Business School Press.

Hastings, R. (2009). Collaboration 2.0. Library Technology Reports, 45(4), 16-18.

Internet World Stats. (2011). World internet users and population stats (March 31, 2011). Retrieved 12 December 2011, from http://www.internetworldstats.com/stats.htm

Jones, M., \& Alony, I. (2008). Blogs - the New Source of Data Analysis. Journal of Issues in Informing Science and Information Technology, 5(1), 433-446.

Kuehn, K. (2005). Collaborate to innovate. Supply \& Demand Chain Executive, 7, 50-51, 53-54.

Liedtka, J. M. (1996). Collaborating across lines of business for competitive advantage. The Academy of Management Executive, 10(2), 20.

Ma, C. (2009). E-collaboration: A universal key to solve fierce competition in tourism industry? International Business Research, 1(4), 65-71. 
Makhija, M. (2003). Comparing the resource-based and market-based views of the firm: Empirical evidence from Czech privatization. Strategic Management Journal, 24(5), 433-451.

Mayrhofer, D., \& Back, A. (2003). Workplace e-collaboration theoretical foundations and practical implications. Unpublished Working Report. Institute of Information Management, University of St. Gallen.

Meixner, O., \& Haas, R. (2008, February 18-22). New product development of a yoghurt dessert via Ecollaboration. Paper presented at the 110th EAAE Seminar 'System Dynamics and Innovation in Food Networks', Innsbruck-Igls, Austria.

Miller, M. (2008). Cloud computing: Web-based applications that change the way you work and collaborate online. Indianapolis, Indiana: Que.

Peter, I. (2004). The history of email. Retrieved 12 December 2011 from http://www.nethistory.info/History\%20of\%20the\%20Internet/email.html

Pfohl, H.-C., Hofmann, E., \& Trumpfheller, M. (2005). Portfolio of business relations: The Darmstadt collaboration diamond. Publications of Darmstadt Technical University, Institute for Business Studies (BWL), 53-79.

Porter, M. E. (1985). Competitive advantage: Creating and sustaining superior performance. New York, NY: The Free Press.

Prahalad, C. K., \& Hamel, G. (1994). Competing for the future. Harvard Business Review, 72(4), 122-128.

Simpson, M., \& Docherty, A. J. (2004). E-commerce adoption support and advice for UK SMEs. Journal of Small Business and Enterprise Development, 11(3), 315-328.

Stern, A. J., \& Hicks, T. (2000). The process of business/environmental collaborations: Partnering for sustainability. Westport, USA: Quorum Books.

Ulbrich, S., Troitzsch, H., van den Anker, F., Plüss, A., \& Huber, C. (2011). How teams in networked organisations develop collaborative capability: Processes, critical incidents and success factors. Production Planning \& Control: The Management of Operations( First published on: 10 February 2011 (iFirst)).

Xu, J., Zhang, J., Harvey, T., \& Young, J. (2008). A survey of asynchronous collaboration tools. Information Technology Journal, 7(8), 1182-1187.

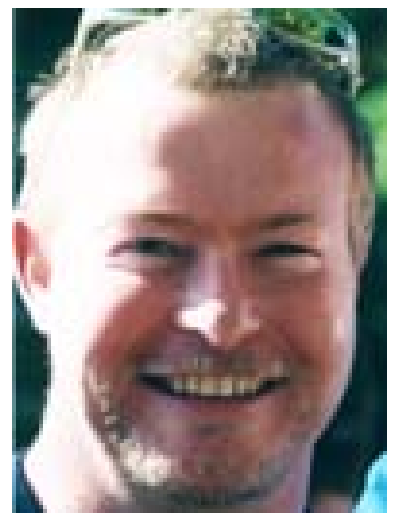

\section{Biographies}

Michael Jones is a lecturer in Organizational Behavior in Australia's University of Wollongong. His recent writings focus on eCollaboration, especially with regard to small to medium enterprises, and on elements of Organizational Psychology. This work has led to a number of competitive grants for research. Early writings dealt with two principle areas; studies of qualitative methods, particularly in the field of grounded theory and computerized techniques for qualitative data analysis; and, organizational behavior, concentrating in areas of motivation and commitment. Michael received his Ph.D. in organizational behavior from the University of Wollongong. 